\title{
Seismic zoning of NE South American intraplate region: Preliminary insights for Probabilistic Seismic Hazard Analysis
}

\author{
José Augusto Silva da Fonsêca, Federal University of Rio Grande do Norte
}

Aderson Farias do Nascimento, Federal University of Rio Grande do Norte

Copyright 2021, SBGf - Sociedade Brasileira de Geofísica.

This paper was prepared for presentation during the $17^{\text {th }}$ International Congress of the Brazilian Geophysical Society held in Rio de Janeiro, Brazil, 8-11 November 2021 (Online Event). Contents of this paper were reviewed by the Technical Committee of the $17^{\text {th }}$ International Congress of the Brazilian Geophysical Society and do not necessarily represent any position of the SBGf, its officers or members. Electronic reproduction or storage of any part of this paper for commercial purposes without the written consent of the Brazilian Geophysical Society is prohibited.

NE Brazil is one of the main active intraplate seismic areas of the South American with recorded magnitudes up to $5.2 \mathrm{mb}$. Although mid-plate earthquake frequency and magnitude are lower when compared to borderplate regions, low attenuation of seismic energy enable even moderate-magnitude earthquakes to pose significant hazard, as it has been demonstrated in the few past decades (i.e., $19805.2 \mathrm{mb}$ Cascavel and 1986 $5.1 \mathrm{mb}$ João Camara earthquakes, with several damaged and collapse of ill-prepared civil constructions). Additionally, the increase of population and proximity to seismic sources, means that even smaller seismic events generate societal inconvenience ("nuisance" seismic events). Seismic Hazard Analysis has been the main seismological tool to evaluate the potential of damage of seismic sources, however the typical lack of correlation with surface geologic features in intraplate areas, complicates the delimitation of its geometry and source mechanism. In this work, we propose seismic zonation for NE South American intraplate region and logic three approach for evaluating numerous scenarios upon uncertainties of seismogenic sources. We determined the seismic zones from the computation of a magnitude-weighted epicentral density map using a $1^{\circ}$ sliding window along intraplate NE South American. After this procedure, we obtained 4 seismic zones where epicenter density is greater: 1 - NW Borborema Province, 2 - NW and 3 - NE Potiguar Basin and 4 reactivated segments of Pernambuco Lineament. However, considering only event clusters which epicenter density is lower, but whose magnitude and intensity have been able to cause a minimum nuisance on the population, we were able to delimit another 3 seismic zones in the State of Maranhão, South Bahia and Sergipe-Alagoas border. Additionally, we have also delimited a wider zone of background source seismicity, where there is not a clear earthquake clustering, but it comprises earthquake locations with considerable magnitudes (typically greater than $3 \mathrm{mR}$ ). Our findings are relevant for seismic hazard analysis once it represents the first approach to quantitatively define seismic zones in this intraplate region. 